\section{Perils and Promise in Defining and Measuring Mindfulness: Observations From Experience}

Kirk Warren Brown and Richard M. Ryan,

University of Rochester

As mindfulness research advances on a variety of fronts, it has become increasingly important to carefully define and measure the construct. In this commentary, we draw from our recent research experience on these topics in addressing four issues of primary concern to Bishop et al: The nature of mindfulness, the role of acceptance in the phenomenon, the relation between mindfulness and meditation, and the measurement of mindfulness in meditative and other contexts.

Key words: attention, awareness, acceptance, mindfulness. [Clin Psychol Sci Prac 11: 242-248, 2004]

$M$ indfulness is increasingly recognized as a phenomenon with functional import for outcomes as diverse as physical health, psychological well-being, work and sport performance, and relationships. Paralleling this recognition is an increased interest in naturally occurring variations in mindfulness and how interventions and practices that facilitate mindfulness actually work. As this research advances, the need for exacting theoretical and operational definitions of mindfulness becomes more salient. However, mindfulness is a deceptively simple concept that is difficult to characterize accurately.

Address correspondence to Kirk Warren Brown, CSP, Meliora Hall, University of Rochester, Rochester, NY 14627-0266. E-mail: kirk@psych.rochester.edu.
Intrepid scholars seeking to do so must enter the shadowy realm of consciousness, the domain from which mindfulness arises. As old as the study of consciousness is within the field of psychology, it nonetheless remains largely uncharted and mysterious territory (Chalmers, 1995). Thus, Bishop, Lau, Shapiro, Carlson, and Anderson (this issue) are to be commended for taking on the bold task of proposing a definition of mindfulness, both conceptually and operationally.

In this commentary, we share our perspectives on Bishop et al.'s theory of, and proposed measurement approach to, mindfulness, drawing upon our own recent research experiences (e.g., Brown \& Ryan, 2003, in press). Specifically, we address four topics of central concern to Bishop et al.: the nature of mindfulness, the relation of acceptance to present-centered attention and awareness, the link between mindfulness and meditative practice, and the measurement of mindfulness in meditative contexts and beyond.

\section{THE PROPOSED DEFINITION OF MINDFULNESS}

Bishop et al. propose a two-component model of mindfulness, incorporating (a) attention and awareness and (b) acceptance. We will discuss each of these in turn. First, in highlighting attention and awareness as central to mindfulness, Bishop et al. are consistent with most scholarly and popular writings on the topic. However, they do not define these terms and often use them interchangeably. Although these terms are commonly used, clarity on their meaning is important, as this bears directly on an understanding of the meaning of mindfulness, its practice, and its measurement.

Awareness refers to the subjective experience of internal and external phenomena; it is the pure 
apperception and perception of the field of events that encompass our reality at any given moment. ${ }^{1}$ Attention is a focusing of awareness to highlight selected aspects of that reality. In everyday awake states, awareness and attention are intertwined. Phrased in gestalt terms, awareness is the field or ground upon which perceived phenomena are expressed, and attention continually pulls "figures" out of that ground to hold them up for closer examination.

Awareness and attention are, of course, the primary features of consciousness, which several authors (e.g., Averill, 1992; Mayer, Chabot, \& Carlsmith, 1997) have distinguished from the other primary mental processing modalities, namely cognition, motives, and emotions. Consciousness serves at least two key functions: monitoring events and experiences as they unfold in real time and directing or controlling the contents of consciousness (Westen, 1999). Mindfulness specifically concerns the monitoring, observing capacity of consciousness. As Bishop et al. point out, mindfulness represents a heightened or sustained attention to and awareness of current events and experience. However, the fact that mindfulness, as a quality of consciousness, can be brought to bear on thought, emotions, and other contents of consciousness means that it cannot be reduced to them. In this sense, labeling mindfulness a "metacognitive skill" (p. 233) is, we believe, misleading.

As noted above, consciousness and cognition are distinct processing modalities. As a cognitive process, metacognition operates within the realm of thought, to monitor and control cognitive activities and to ensure that cognitive goals have been met (Schwartz \& Perfect, 2002). Specifically, these processes consist of planning and monitoring cognitive activities and checking or testing goal-related outcomes. Here is a common example: After reading this article, a reader may question herself about the ideas discussed, with the cognitive goal of better understanding the text. Selftesting in this way is a typical metacognitive strategy for monitoring comprehension. If the reader concludes that her comprehension is less than adequate, she can then take further action (e.g., re-reading the article and selftesting again) to ensure that she meets her goal of text comprehension.

Mindfulness differs from such metacognitive processes in that its mode of operation is perceptual, operating upon thought, as well as upon emotion and other contents of consciousness, rather than within them. Simply put, if mindfulness involves observing thought, including thoughts about thoughts, it cannot be thought. The observing capacity that defines mindfulness is one reason why it has been associated with "psychological freedom" (Martin, 1997). Because it provides a "bare display of what is taking place" (Shear \& Jevning, 1999, p. 204) it is not subject to the distortions and biases inherent in cognition and, evidence suggests, in metacognition as well (Glenberg, Wilkinson, \& Epstein, 1982).

Distinctions between attention and awareness may also prove important to the study of mindfulnesspromoting practices. Bishop et al. present two views on mindfulness practice, one highlighting focused attention, the other emphasizing conscious awareness. Specifically, they note that in meditation, "the client ... attempts to maintain attention on a particular focus, most commonly the somatic sensations of his or her own breathing" (p. 232). Yet later they write that mindfulness "begins with making a commitment to maintain an attitude of curiosity about where the mind wanders whenever it inevitably drifts away from the breath.... All thoughts, feelings and sensations that arise are initially seen as relevant and therefore subject to observation" (p. 233). Citing Hayes, Strosahl, and Willson, they write, "It involves a conscious decision to abandon one's agenda to have a different experience and an active process of 'allowing' current thoughts, feelings and sensations" (p. 233).

Bishop et al. do not make clear how these two forms of mindfulness meditation are related, and the forms appear contradictory. How can one "maintain attention on a particular focus" and at the same time be curious about where the mind wanders? If one is encouraged to "abandon one's agenda," doesn't this also include the self-imposed agenda to maintain attentional focus on the breath? The apparent contradiction here can be resolved by understanding each form of mindfulness meditation as distinct aspects of meditative practice that may play different roles in how mindfulness is realized.

A number of Buddhist scholars and teachers have described two corresponding forms of meditative practice: concentration and awareness/insight (e.g., Kapleau, 1980; Kornfield, 1993; Rahula, 1974). Concentration 
meditation involves focusing attention fixedly on an internal object such as the breath, a word, or a phrase (mantra), or on an external object, such as a candle or mandala. When attention strays from the object-into thought, for example - it is gently but firmly brought back to the object. Concentration can produce highly positive experiences of peacefulness, tranquillity and mental silence, and it can set the stage for awareness meditation (e.g., Rahula, 1974), as will be described shortly. In contrast, awareness or insight meditation brings consciousness to bear on the moment-to-moment flow of our present experience-sense impressions, thoughts, feelings and so on-and the need lessens for an attentional object on which to focus. In this form, attention gives way to a heightened awareness of the ongoing stream of (ap)perceptual phenomena. While concentration meditation tends to have a calming effect on the mind, awareness meditation is active and energy gathering. Many scholars believe that both forms of meditation are important: Concentration trains the attentional capacity of the mind, while active observation of the ever-changing present encourages insight into the nature of conscious experience through a clear "view" of what makes up our world of consciousness. It can also facilitate access to experiences that normally lie outside conscious awareness (Kornfield, 1993; Wilber, 2000).

Some meditative traditions-Zen for example-use a stage model of training that incorporates both forms of meditation (e.g., Kapleau, 1980). Students are first encouraged to practice concentration (by counting the breath or attending to its sensations) to strengthen the capacity to sustain attention over time before turning to awareness practice. Adherence to this sequential model comes in recognition of the fact that, in awareness meditation, the mind can become easily lost in thought, mental images, or emotions without the power of sustained attention to keep one attuned to present experience. Stage models sometimes imply a hierarchical ordering of importance, but one form of meditation is not necessarily "better" than the other; much depends on the outcome of interest. In daily life, for example, the insight gained through heightened awareness can only be translated into concrete action by bringing focused attention to bear on our behavior or on the task at hand (cf. Martin, 1997).

\section{What role does acceptance play in mindfulness?}

Bishop et al. argue for a second component of mindfulness beyond attention and awareness of the present, namely acceptance. When we began our own work on developing a self-report measure of dispositional mindfulness, we started from the theoretical position, as do Bishop et al., that acceptance is a primary component of mindfulness. We also hypothesized that attention/ awareness and acceptance are related, as Bishop et al.'s proposed definition suggests. The first self-report scale that we developed had two factors. One was labeled "presence" and contained items assessing presentcentered attention and awareness. The other factor was labeled "acceptance" and included items such as "When unpleasant thoughts arise, I don't feel I have to put my attention somewhere else" and "I don't like feelings like fear or anger, so I don't allow myself to experience them" (reverse scored). These two factors, each with satisfactory psychometric properties, were correlated (in the .20 to .35 range across different samples), and confirmatory factor analyses found that a second-order factor model, in which the two factors were nested under an overarching "mindfulness" factor, provided a satisfactory fit. However, our convergent, discriminant, and criterion validity research showed, across several large samples, that the acceptance factor provided no explanatory advantage over that shown by the presence factor alone (Brown \& Ryan, 2001).

To illustrate, Table 1 provides zero-order correlations between the two factors and a number of indicators of well-being in two samples. Visual inspection suggests that the presence factor was more highly correlated with many of these indicators than was the acceptance factor. This was verified using $t$-tests to compare the sizes of the $r$ values (Cohen \& Cohen, 1983). For most of the well-being indicators, the presence factor correlated more strongly than the acceptance factor at $p<.01$. For pleasant affect and physical symptoms, the $r$ value differences were significant at $p<.05$; the correlations of presence and acceptance with PANAS positive affect and PWB autonomy did not differ significantly from each other.

The presence factor alone also generally showed correlations with well-being equal in magnitude to those of the combined presence and acceptance factors, as represented by the total mindfulness scale score, $p \mathrm{~s}>.05$ 
Table 1. Correlations of presence, acceptance, and total mindfulness with psychological well-being indicators

\begin{tabular}{|c|c|c|c|}
\hline Scale & Presence & Acceptance & Total \\
\hline \multicolumn{4}{|l|}{ Traits and attributes } \\
\hline $\begin{array}{l}\text { NEO-PI Neuroticism }{ }^{\mathrm{a}} \\
\text { NEO-FFI Neuroticism }^{\mathrm{b}} \\
\text { RRQ Rumination }^{\mathrm{b}} \\
\text { MSEI Self esteem }^{\mathrm{b}} \\
\text { TMMS Emotional intelligence }^{\mathrm{a}}\end{array}$ & $\begin{array}{r}-.53^{* * * *} \\
-.46^{* * * *} \\
-.47^{* * * *} \\
.38^{* * * *} \\
.50^{* * * *}\end{array}$ & $\begin{array}{l}-.25^{* * * *} \\
-.24^{* * * *} \\
-.22^{* * * *} \\
.21^{* * * *} \\
.18^{* * *}\end{array}$ & $\begin{array}{r}-.52^{* * * *} \\
-.45^{* * * *} \\
-.45^{* * * *} \\
.37^{* * * *} \\
.47^{* * * *}\end{array}$ \\
\hline \multicolumn{4}{|l|}{ Emotional disturbance } \\
\hline $\begin{array}{l}\text { CES-D Depression } \\
\text { STAI Anxiety }\end{array}$ & $\begin{array}{l}-.42^{* * * *} \\
-.45^{* * * *}\end{array}$ & $\begin{array}{l}-.26^{* * * *} \\
-.29^{* * * *}\end{array}$ & $\begin{array}{l}-.43^{* * * *} \\
-.46^{* * * *}\end{array}$ \\
\hline \multicolumn{4}{|l|}{ Emotional-subjective well-being } \\
\hline $\begin{array}{l}\text { Pleasant affect } \mathrm{b}^{\mathrm{b}} \\
\text { Unpleasant affect } \\
\text { PANAS Positive affect } \\
\text { PANAS Negative affect } \\
\text { TSWLS Life satisfaction }\end{array}$ & $\begin{array}{r}.32 * * * * \\
-.38^{* * * *} \\
.30^{* * * *} \\
-.46^{* * * *} \\
.30^{* * * *}\end{array}$ & $\begin{array}{l}.19^{* * *} \\
-.20^{* * *} \\
.23^{* * *} \\
-.25^{* * * *} \\
.14^{* *}\end{array}$ & $\begin{array}{r}.32^{* * * *} \\
-.37^{* * * *} \\
.33^{* * * *} \\
-.45^{* * * *} \\
.29^{* * *}\end{array}$ \\
\hline \multicolumn{4}{|l|}{ Eudaimonic well-being } \\
\hline $\begin{array}{l}\text { SVS Vitality } \\
\text { MAP Self actualization }{ }^{\mathrm{b}} \\
\text { PWB Autonomy } \\
\text { PWB Competence } \\
\text { PWB Relatedness } \\
\text { PW }\end{array}$ & $\begin{array}{l}.44^{* * * *} \\
.43^{* * * *} \\
.37 * * * * \\
.44^{* * * *} \\
.31^{* * * *}\end{array}$ & $\begin{array}{l}.09 \\
.24^{* * * *} \\
.29^{* * * *} \\
.24^{* * * *} \\
.09\end{array}$ & $\begin{array}{l}.38^{* * * *} \\
.43^{* * * *} \\
.40^{* * * *} \\
.43^{* * * *} \\
.26^{* * * *}\end{array}$ \\
\hline \multicolumn{4}{|l|}{ Physical well-being } \\
\hline $\begin{array}{l}\text { Reported physical symptoms } \\
\text { HSCL Somatization }^{\mathrm{a}}\end{array}$ & $\begin{array}{l}-.26^{* * * *} \\
-.40^{* * * * *}\end{array}$ & $\begin{array}{l}-.13^{* *} \\
-.23^{* * * *}\end{array}$ & $\begin{array}{l}-.26^{* * * * *} \\
-.41^{* * * *}\end{array}$ \\
\hline
\end{tabular}

Note. Superscripts $a$ and $b$ refer to samples with $N=313$ and $N=327$, respectively.

CES-D Depression $=$ Center for Epidemiologic Studies Depression Scale (Radloff, 1977); HSCL Somatization = Hopkins Symptom Checklist (Derogatis, Lipman, Rickels, Uhlenhuth, \& Covi, 1974); MAP Self actualization $=$ Measure of Actualization of Potential (Lefrançois, Leclerc, Dubé, Hébert, \& Gaulin, 1997); MSEl Self esteem = Multidimensional SelfEsteem Inventory (O'Brien \& Epstein, 1988); NEO-PI Neuroticism = NEO Personality Inventory (Costa \& McCrae, 1992); NEO-FFI Neuroticism = NEO Five Factor Inventory (Costa \& McCrae, 1992); PANAS Positive affect, Negative affect $=$ Positive and Negative Affect Scales (Watson, Clark, \& Tellegen, 1988); Pleasant affect $=$ Pleasant hedonic valence $($ Diener \& Emmons, 1984); PWB Autonomy, Competence, Relatedness = Personal Well-Being Scales (Ryff, 1989); Reported physical symptoms $=($ Larsen \& Kasimatis, 1991); RRQ Rumination = Rumination-Reflection Questionnaire (Trapnell \& Campbell, 1999); STAI Anxiety = State Trait Anxiety Inventory (Spielberger, 1983); SVS Vitality = Subjective Vitality Scale (Ryan \& Frederick, 1997); TSWLS Life satisfaction = Temporal Satisfaction With Life Scale (Pavot, Diener, \& Suh, 1998); TMMS Emotional intelligence $=$ Trait Meta-Mood Scale (Salovey, Mayer, Goldman, Turvey \& Palfai, 1995);

Unpleasant affect $=$ Unpleasant hedonic valence (Diener \& Emmons, 1984).

${ }^{* *} p<.01,{ }^{* * *} p<.001,{ }^{* * * *} p<.0001$.

(see Table 1). The correlations of presence with SVS vitality and PWB relatedness were in fact higher than those of the total scale score, $p$ s $<.05$. These and other findings suggested to us that as a distinct construct, acceptance is functionally redundant in mindfulness. We then focused our efforts on the presence construct, and items from this factor were incorporated into a second-generation measure: the Mindful Attention Awareness Scale (MAAS; Brown \& Ryan, 2003).
We continued to believe, however, that acceptance is important to mindfulness, but not in the way we first thought. We have operationally defined mindfulness as an open or receptive attention to and awareness of ongoing events and experience (e.g., Brown \& Ryan, 2003), and the MAAS measures this by asking respondents to rate the frequency with which their day-to-day consciousness reflects this quality. The redundancy of the acceptance factor that we found in our preliminary work may be because mindfulness, as we define it here, subsumes an acceptance of what occurs.

Specifically, embedded within the capacity to sustain attention to and awareness of what is occurring is an openness to and acceptance of it. Such presence means "taking each moment as it comes." When an individual does not accept what is occurring at a given moment, a natural reaction is to limit awareness and redirect attention, to seek to avoid or escape from the event or experience-mentally, behaviorally, or in some other way. To turn away is to become (intentionally) inattentive and unaware - that is, to cease to be present, or to be mindless. Kornfield noted that, "to pay attention carefully is ... a surrender to what is actually happening in each moment without trying to alter or change or put a conceptual framework around it. ... This cultivates a state of mind which allows us to be open, to observe and experience fully the entire range of mental and physical reality without either suppressing it or acting it out" (1993, pp. 56-57, emphasis added). Likewise, Tolle (1999) asserts that in giving "fullest attention to whatever the moment presents ... implies that you also completely accept what is, because you cannot give your full attention to something and at the same time resist it" (p. 56). Without regular or consistent, open, and non-judgmental observation, mindful states, as simply defined by frequent attention to and awareness to what is occurring, would be uncommon, resulting in low scores on a mindfulness scale that assesses attention and awareness, as the MAAS does.

\section{IS MINDFULNESS SPECIFIC TO MEDITATIVE CONTEXTS?}

Bishop et al. emphasize the role of meditation in cultivating mindfulness. They note, for example, the role of attentional focus on the breath as a means to 
experiencing internal events. In fact, in distinguishing their conceptualization of mindfulness from that of Langer (e.g., 1989), they de-emphasize mindfulness of external stimuli, stating instead that "our own definition emphasizes ... attention to primarily internal stimuli (thoughts, feelings and sensations)" (p. 235, emphasis in original). We have both conceptual and empirical concerns in binding mindfulness to meditation and to the consciousness of primarily internal phenomena that meditation typically involves.

Along with Bishop et al., we believe that meditative practices can be an effective route to the enhancement of mindfulness. Yet, mindfulness is not merely a product of meditation. As we have argued elsewhere (Brown \& Ryan, 2003), mindfulness is an inherent, natural capacity of the human organism. Dzogchen teaching has called this inherent capacity "unfabricated mindfulness" (see Goldstein, 2002). Our research (e.g., Brown \& Ryan, 2003; Carlson \& Brown, 2003; Levesque \& Brown, 2003) has shown that individuals in the general population, most of whom have had no formal meditation experience, reliably differ in the propensity to be mindful, measured using both a dispositional measure (the MAAS) and on a day-to-day basis using a state measure derived from the MAAS. Further, this research has shown that these natural individual differences have significant self-regulatory and psychological well-being consequences.

In accord with our theorizing that mindfulness involves a present-centered attention to and awareness of all accessible events and experiences, our measure taps mindfulness of both internal and external stimuli. By tying mindfulness primarily to the consciousness of internal stimuli, Bishop et al. imply that mindfulness mainly has relevance to situations in which there are no external demands to negotiate, such as in meditation. Yet a primary benefit of meditative practice is that it can change how individuals behave "off the cushion" in their day-to-day lives (e.g., Kabat-Zinn, 1993), bringing mindful presence to bear not only on internal events, but also on our daily social and physical worlds. In this view, the concept of mindfulness is less restricted in scope, and the practice of mindfulness can be broadly considered.

Bishop et al. emphasize that meditation can be a powerful vehicle to enhance mindfulness, and we agree. Our research with Zen practitioners has shown that meditation practice is associated with greater mindfulness (Brown \& Ryan, 2003). This research also showed, however, that dispositional mindfulness is related to the extent to which individuals carried their practice over into their daily lives. In addition, we believe, as Bishop et al. also appear to, that it is important to remain open to the possibility that mindfulness may be cultivated through practices other than meditation. For example, some theorists (Epstein, 1990; Martin, 1997; Wilber, 2000) have suggested that a variety of forms of psychotherapy may facilitate open or receptive attention and awareness to psychological and/or behavioral events and experience. Personality and therapeutic traditions discussing this point have ranged from psychodynamic (Freud, 1912/963) to Gestalt (Perls, 1973) to cognitive behavioral (Safran \& Segal, 1990) approaches. Research underway in our laboratory is testing whether psychotherapy can enhance clients' levels of mindfulness.

Measurement in meditative contexts. Bishop et al.'s development of a measure of mindfulness for use in meditative contexts could potentially be very useful in exploring the phenomenology and impact of mindful states (cf., Forte, Brown, \& Dysart, 1987/1988). Bishop et al.'s other goals for such a measure, including the investigation of meditational processes, are laudable. We wish only to add a note of caution regarding their plan for assessing mindfulness "in reference to an immediately preceding [mindfulness] session" (p. 237) or immediately post-training in longitudinal programs. If, as can be assumed in mindfulness-training contexts, respondents are aware of the goal to enhance mindfulness, care will have to be taken to lessen the effects of social desirability and demand characteristics. Longitudinal or experimental research will also be needed to ensure that qualities assumed to follow from mindfulness can be distinguished from measures of mindfulness. This points, more generally, to the importance of showing that a new measure has predictive value, particularly, we believe, for outcomes such as mental health, equanimity, compassion, generosity, wisdom, and other human potentialities that have traditionally been associated with mindfulness and meditation (Shapiro \& Walsh, 2003; Walsh, 1996). 


\section{CONCLUSION}

The field of mindfulness studies is still in an early stage of development. Much of the research to date has concerned the efficacy of mindfulness training to enhance well-being in clinical contexts, and the results have been quite positive (Baer, 2003). As researchers begin to explore the applications of mindfulness in more varied contexts and populations, scientific progress will rest upon our definitions and measures of the phenomenon. In this regard we share Bishop et al.'s deep interest in basic questions concerning mindfulness: What is it? How is it expressed and how is it best measured? How does mindfulness operate to produce salutary outcomes? Given the depth and complexity of the phenomenon, debate over such basic issues is to be expected and wellconducted empirical research can help to refine both answers and questions. Equally importantly, the study of basic questions will also help to more firmly place mindfulness within a network of other, established fields of study, and thereby enhance our understanding of human nature as a whole.

\section{NOTES}

1. The term "perception" is typically used to refer to the consciousness of external stimuli received through the five senses, while philosophical discourse often refers to "apperception" as the consciousness of internal events and experience (Depraz, Varela, \& Vermersch, 2000).

\section{REFERENCES}

Averill, J. R. (1992). The structural bases of emotional behavior: A metatheoretical analysis. Review of Personality and Social Psychology, 13, 1-24.

Baer, R. A. (2003). Mindfulness training as a clinical intervention: A conceptual and empirical review. Clinical Psychology: Science and Practice, 10, 125-143.

Bishop, S. R., Lau, M., Shapiro, S. L., Carlson, L., \& Anderson, N. D. (2004). Mindfulness: A proposed operational definition. Clinical Psychology: Science and Practice, 11, 230241.

Brown, K. W., \& Ryan, R. M. (2001). Testing a two-factor model of mindfulness. Unpublished data, University of Rochester.

Brown, K. W., \& Ryan, R. M. (2003). The benefits of being present: Mindfulness and its role in psychological wellbeing. Journal of Personality and Social Psychology, 84, 822-848.
Brown, K. W., \& Ryan, R. M. (in press). Fostering healthy self-regulation from within and without: A Self-Determination Theory perspective. In P. A. Linley \& S. Joseph (Eds.), Positive psychology in practice. Hoboken, NJ: Wiley.

Carlson, L. E., \& Brown, K. W. (2003). Validation of the Mindful Attention Awareness Scale in a cancer population. Manuscript submitted for publication.

Chalmers, D. J. (1995, December). The puzzle of conscious experience. Scientific American, 80-86.

Cohen, J., \& Cohen, P. (1983). Applied multiple regression/correlation analysis for the behavioral sciences (2nd ed.). Hillsdale, NJ: Lawrence Erlbaum.

Costa Jr., P. T., \& McCrae, R. R. (1992). Revised NEO personality inventory (NEO PI-R) and NEO five-factor inventory (NEO-FFI): Professional manual. Odessa, FL: Psychological Assessment Resources.

Depraz, N., Varela, F. J., \& Vermersch, P. (2000). The gesture of awareness: An account of its structural dynamics. In M. Velmans (Ed.), Investigating phenomenal consciousness: New methodologies and maps (pp. 121-136). Philadelphia, PA: John Benjamins.

Derogatis, L. R., Lipman, R. S., Rickels, K., Uhlenhuth, E. H., \& Covi, L. (1974). The Hopkins Symptom Checklist (HSCL): A self-report symptom inventory. Behavioral Science, 19, 1-15.

Diener, E., \& Emmons, R. A. (1984). The independence of positive and negative affect. Journal of Personality and Social Psychology, 47, 1105-1117.

Epstein, M. (1990). Psychodynamics of meditation: Pitfalls on the spiritual path. Journal of Transpersonal Psychology, 22, 17-34.

Forte, M., Brown, D. P., \& Dysart, M. (1987/1988). Differences in experience among mindfulness meditators. Imagination, Cognition \& Personality, 7, 47-60.

Freud, S. (1963). Recommendations for physicians on the psycho-analytic method of treatment. In P. Reiff (Ed.), Freud: Therapy and technique (pp. 117-126). New York: Collier. (Original work published 1912).

Glenberg, A. M., Wilkinson, A. C., \& Epstein, W. (1982). The illusion of knowing: Failure in the self-assessment of comprehension. Memory \& Cognition, 10, 597-602.

Goldstein, J. (2002). One dharma: The emerging western Buddhism. San Francisco: Harper Collins.

Kabat-Zinn, J. (1993). Mindfulness meditation: Health benefits of an ancient Buddhist practice. In D. Goleman \& J. Gurin (Eds.), Mind/body medicine (pp. 259-275). Yonkers, NY: Consumer Reports Books.

Kapleau, P. (1980). The three pillars of Zen. Garden City, NY: Anchor Press. 
Kornfield, J. (1993). The seven factors of enlightenment. In R. Walsh \& F. Vaughan (Eds.), Paths beyond ego: The transpersonal vision (pp. 56-59). Los Angeles: Tarcher.

Langer, E. (1989). Mindfulness. Reading, MA: Addison Wesley.

Larsen, R. J., \& Kasimatis, M. (1991). Day-to-day physical symptoms: Individual differences in the occurrence, duration, and emotional concomitants of minor daily illnesses. Journal of Personality, 59, 387-423.

Lefrançois, R., Leclerc, G., Dubé, M., Hébert, R., \& Gaulin, P. (1997). The development and validation of a self-report measure of self-actualization. Social Behavior and Personality, $25,353-365$

Levesque, C. S., \& Brown, K. W. (2003). Overriding motivational automaticity: Mindfulness as a moderator of the influence of implicit motivation on day-to-day behavior. Manuscript submitted for publication.

Martin, J. R. (1997). Mindfulness: A proposed common factor. Journal of Psychotherapy Integration, 7, 291-312.

Mayer, J. D., Chabot, H. F., \& Carlsmith, K. (1997). Conation, affect, and cognition in personality. In G. Matthews (Ed.), Cognitive science perspectives on personality and emotion (pp. 31-63). Amsterdam: Elsevier.

O'Brien, E. J., \& Epstein, S. (1988). MSEI: The Multidimensional Self-esteem Inventory, professional manual. Odessa, FL: Psychological Assessment Resources.

Pavot, W., Diener, E., \& Suh, E. (1998). The Temporal Satisfaction With Life Scale. Journal of Personality Assessment, 70, 340-354.

Perls, F. (1973). The gestalt approach \& eye witness to therapy. New York: Bantam.

Radloff, L. S. (1977). The CES-D scale: A self-report depression scale for research in the general population. Applied Psychological Measurement, 1, 385-401.

Rahula, W. S. (1974). What the Buddha taught. New York: Grove Press.

Ryan, R. M., \& Frederick, C. (1997). On energy, personality, and health: Subjective vitality as a dynamic reflection of well-being. Journal of Personality, 65, 529-565.

Ryff, C. (1989). Happiness is everything, or is it? Explorations on the meaning of psychological well-being. Journal of Personality and Social Psychology, 57, 1069-1081.
Safran, J. D., \& Segal, Z. V. (1990). Interpersonal process in cognitive therapy. New York: Basic.

Salovey, P., Mayer, J. D., Goldman, S. L., Turvey, C., \& Palfai, T. F. (1995). Emotional attention, clarity, and repair: Exploring emotional intelligence using the trait metamood scale. In J. W. Pennebaker (Ed.), Emotion, disclosure, and health (pp. 125-154). Washington, DC: American Psychological Association.

Schwartz, B. L., \& Perfect, T. J. (2002). Introduction: Toward an applied metacognition. In T. J. Perfect \& B. L. Schwartz (Eds.), Applied metacognition (pp. 1-11). New York: Cambridge University Press.

Shapiro, S. L., \& Walsh, R. (2003). An analysis of recent meditation research and suggestions for future directions. The Humanistic Psychologist, 31, 86-114.

Shear, J., \& Jevning, R. (1999). Pure consciousness: Scientific exploration of meditation techniques. In F. J. Varela \& J. Shear (Eds.), The view from within (pp. 189-209). Thorverton, UK: Imprint Academics.

Spielberger, C. D. (1983). Manual for the State-Trait Anxiety Inventory: STAI (Form Y) Palo Alto, CA: Consulting Psychologists Press.

Tolle, E. (1999). The power of now. Novato, CA: New World Library.

Trapnell, P. D., \& Campbell, J. (1999). Private selfconsciousness and the five factor model of personality: Distinguishing rumination from reflection. Journal of Personality and Social Psychology, 76, 284-304.

Walsh, R. (1996). Meditation research: The state of the art. In B. W. Scotton, A. B. Chinen \& J. R. Battista (Eds.), Textbook of transpersonal psychiatry and psychology (pp. 167175). New York: Basic Books.

Watson, D., Clark, L. A., \& Tellegen, A. (1988). Development and validation of brief measures of positive and negative affect: The PANAS scales. Journal of Personality and Social Psychology, 54, 1063-1070.

Westen, D. (1999). Psychology: Mind, brain, and culture (2nd ed.). New York: Wiley.

Wilber, K. (2000). Integral psychology: Consciousness, spirit, psychology, therapy. Boston: Shambhala.

Received November 11, 2003; revised January 20, 2004; accepted January 22, 2004. 